\title{
Importance of English in Medical Education
}

\author{
Anshita Batta
}

\begin{abstract}
For speedy developments in the universe of medicine, the medical education, the Medical Council of India (MCI) has devised competencybased undergraduate curriculum (CBUC) for medical graduation. The new curriculum is proposed to be "more learner-centric, patient-centric, gender-sensitive, outcome-oriented and environment appropriate in keeping with the global trends." The outgoing medical graduate has to perform multiple roles as a clinician, leader of healthcare team, communicator with patients, families, colleagues, and community and become a life-long learner committed to continuous improvement. This is expected to be achieved through a foundation course that would allow the students from diverse educational streams and backgrounds to transition appropriately. The course would focus on "Attitude, Ethics and Communication (AETCOM) Competencies." He should be able to demonstrate ability to establish professional relationships with patients and families that are positive, understanding, humane, ethical, empathetic, and trustworthy. He must also demonstrate ability to communicate with patients in a manner respectful of patient's preferences, values, prior experience, beliefs, confidentiality, and privacy. Obviously for gaining expertise in medicine and medical communication, language that is commonly and internationally well understood is English. Need for communicating in English in India is more important. True, that most students admitted to medical colleges are selected through a national process of competition, they come from diverse backgrounds. Many of them might have taken tests in their vernacular because they were in vernacular schools and studied most of the subjects, including biology, in vernacular and not in English. More than education of language, communication skills are more important communication is the ability you use when giving and receiving different kinds of information. Some examples include communicating new ideas, feelings, or even an update on your project. Communication skills involve listening, speaking, observing, and empathizing.
\end{abstract}

Keywords: Communication, Communication skills, Medical English.

Journal of Medical Academics (2019): 10.5005/jp-journals-10070-0042

\section{INTRODUCTION}

Modern era has made innumerable inventions, innovations, and discoveries during the last few decades and these are briskly growing. The subjects that have seen fastest changes are cybernetics, medicine, and medical technology. We are witnessing overlap and blur of engineering and medicine. When Indian Institutes of Technology seek to own a hospital, and teach medicine, time becomes ripe to rethink and evolve the curriculum in medicine. Telemedicine is making geographical boundaries irrelevant. Increasingly, communicating clearly and quickly is becoming important.

Looking into such speedy developments in the universe of medicine, the medical education is undergoing progressive evolution. The Medical Council of India (MCI) has, during 2018, devised a competency-based undergraduate curriculum (CBUC) for medical graduation. The new curriculum is proposed to be "more learner-centric, patient-centric, gender-sensitive, outcome-oriented and environment appropriate. The result is an outcome driven curriculum which conforms to global trends." ${ }^{1}$ The underlying feature of the revised curriculum is that the outgoing medical graduate must be able to perform multiple roles as a clinician, leader of healthcare team, communicator with patients, families, colleagues, and community and become a life-long learner committed to continuous improvement. This is expected to be achieved through a foundation course that would allow the students from diverse educational streams and backgrounds to transition appropriately. The course would focus on 'Attitude, Ethics and Communication (AETCOM) Competencies"2 of skills and knowledge and above all a professional, who is committed to excellence, is ethical, responsive, and accountable to patients, community, and professional. As a communicator with patients, families, colleagues,
Department of Physiology, Army College of Medical Sciences, New Delhi, Delhi, India

Corresponding Author: Anshita Batta, Department of Physiology, Army College of Medical Sciences, New Delhi, Delhi, India, Phone: +91 9810765279, e-mail: anshibatta@gmail.com

How to cite this article: Batta A. Importance of English in Medical Education. J Med Acad 2019;2(2):58-60.

Source of support: Nil

Conflict of interest: None

and community, the medical graduate must demonstrate ability to communicate adequately, sensitively, effectively, and respectfully with patients in a language that the patient understands and in a manner that will improve patient satisfaction and healthcare outcomes. He should be able to demonstrate ability to establish professional relationships with patients and families that are positive, understanding, humane, ethical, empathetic, and trustworthy. He must also demonstrate ability to communicate with patients in a manner respectful of patient's preferences, values, prior experience, beliefs, confidentiality, and privacy.

\section{English Language for International COMMUNICATION}

The need for learning English language has been clearly stated by Dr Javier Lucaya, Chairman of Radiology, Vail d'Hebron Hospital, Barcelona, Spain, "I may be exaggerating, but I do think that unless you know enough English to read the medical literature, it is almost impossible to keep up to date with medical advances. I honestly feel that English should be a compulsory subject at medical school." 
Similarly, for the students of medical sciences and for the medical practitioners from non-English-speaking countries, Ribes ${ }^{4}$ has emphasized, "The need for English as a professional language in medicine is nowadays beyond doubt. Scientific literature and the internet are just two examples that reveal the overriding necessity for understanding and expressing ourselves in written and spoken English." In its home page, the Humanitas University ${ }^{5}$ in Italy has particularly emphasized that the 6-year degree program in Medicine and Surgery is "taught in English." The program strongly focuses on enhancing the medical skills of a doctor through the integration and acquisition of the basic competences.

Obviously for gaining expertise in medicine and medical communication, language that is commonly and internationally well understood is English. Need for communicating in English in India is more important. True, that most students admitted to medical colleges are selected through a national process of competition, they come from diverse backgrounds. Many of them might have taken tests in their vernacular because they were in vernacular schools and studied most of the subjects, including biology, in vernacular and not in English. Another reason is that entry to the medical colleges is a quantum jump in terms of standard of education. The students suddenly feel that they have come out of their hidden foundation to a visible multistoried tower. And almost all the textbooks are published in English.

"Quote" by Nelson Mandela:

Without language, one cannot talk people and understand them; one cannot share their hopes and aspiration, grasp their history, appreciate their poetry, or savour their songs.

-Nelson Mandela

Let me share my personal experience. I can speak and understand Hindi, Punjabi, and English fluently. When I joined the medical college at Chennai, I faced the patients who neither understood nor spoke any of these languages. I rushed to learn Tamil_speaking, listening, and understanding. Of course, I still do not know "how to write" because the prescriptions I wrote were in English. Language is a bridge between the student and the teacher and textbooks. In modern times, English has emerged as the language of science, medical education, and medical professionals, for conducting research, searching the literature, for seminars, and conferences. It is certainly not an exaggeration to state that without the knowledge of English it is almost impossible to keep up to date with medical advances. Fluency in English would speed up learning and understanding medical subjects. It is for these reasons that the proposed foundation course has emphasized that the medical graduates should secure basic skills and knowledge of both the local language as well as English.

During the last two decades, many corporates have established and invested in state-of-the-art medical facilities of international standards in India. All such hospitals seek international accreditation. One of their principal objectives is to seek international clients through medical tourism. To achieve that purpose, the hospitals seek medical personnel having fluency in English conversation, written communication, and understanding.

\section{The Medical English}

There could be many more reasons to justify that English needs to be taught to the new entrants in medical education (Fig. 1). It is necessary that teaching English should be made compulsory during the first year. Leave apart those from vernacular background, students having qualified from English-medium schools would be

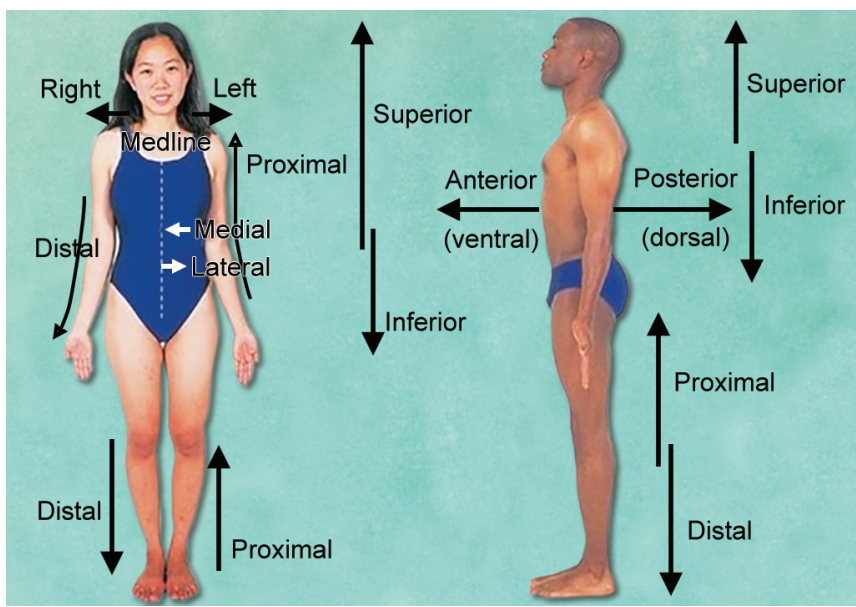

Fig. 1: Anatomical terms-a challenge for newcomers

bewildered with the medical jargon and abbreviations that would be used during the first week of anatomy class. Simple terms like "proximal," "distal," "ventral," and "dorsal" would sound like words from another planet. From arm and leg bones learnt in schools, you move to radius-ulna and tibia-fibula. Eye, ear, and nose are respectively spoken as ophthalmic, cochlear, and nasal. Heart and arteries become cardiac and vascular. Such confusion can hamper the progress of students as they face the difficulty in understanding and internalization of medical terms and the basics for application.

\section{SKILLS}

The 1-month foundation course proposed by the $\mathrm{MCl}$ at the beginning of the MBBS course is expected "to sensitise the fresh medical student with the required knowledge and skills that will assist him/her in acclimatizing to the new professional environment." The skills module of the course requires students to be trained in prior to entering. "Skills which are needed to enable students from diverse backgrounds (including different Boards, language of instruction, culture and varied degrees of technological exposure) to appreciate and accommodate the similarities and differences in medical practice and to feel at par with each other." More than education of language, communication skills are more important. Communication is the ability you use when giving and receiving different kinds of information. Some examples include communicating new ideas, feelings, or even an update on your project. Communication skills involve listening, speaking, observing, and empathizing. It is also helpful to understand the differences in how to communicate through face-to-face interactions, phone conversations, and digital communications like e-mail and social media. There are different types of communication skills you can learn and practice to help you become an effective communicator. Many of these skills work together, making it important to practice communication skills in different contexts whenever possible. Most important communication skills are listening, reading speaking, talking, and writing.

\section{Communication Skills to Master}

\section{Reading}

Teaching of medical English has to begin with skill in reading. It is a first step in the learning of any language. Reading professional books and manuscripts is an essential task for everyone who 
wants to be informed of the medical terminologies in a constantly changing environment. Familiarity with some terms and grammatical structures will make text books easier to read and, therefore, allow you to get more accurate information. The goal in terms of reading would be to feel comfortable with English. In the beginning, reading will be a troublesome task because there are a lot of words that are difficult to pronounce. There would be many whose spellings and meaning would be very difficult to internalize and speak. Many a times, there would be a need to refer to a dictionary of medical terms or seek repeated help from the teachers and the colleagues. Lack of skill to pronounce and read can damage the self-confidence and thus ability to learn. The magic lies in not giving up but continuing efforts in developing the skill of reading medical English. Once the skill to read is mastered, the medical terminologies would sound easy.

\section{Listening}

The speed of learning any language is directly dependent on our skill of listening. Listening is the most important skill to optimize. Be careful and attentive while attending lecture, seminar, meeting, or a conference. It is the easiest way to get valuable information and knowledge without talking or interacting. Pay attention to the information and message being given by the speakers. It is established that the capacity of person to understand the subject being talked about is greater than the ability to talk. One can understand almost everything in a complex talk about an unknown subject about which he would be barely able to say a few sentences. It is therefore of paramount importance to develop the listening skill. Other steps that can be helpful in developing listening skills are listening to ourselves reading out loud, watching movies in English with English subtitles, TV news bulletins, and, of course, conferences.

\section{Speaking}

Next step is to begin speaking in English. After having developed the skills of reading and listening, it is time to learn and gradually master the art of speaking. Speaking is a difficult skill and needs sustained effort. There are many problems such as finding the correct words to speak and that too with correct pronunciation. Once you know that your speech is incorrect or wrongly pronounced, you develop fear and apprehension about your ability to speak. The lack of self-confidence leads to avoiding opportunity to speak. To be fluent in speaking in English language becomes an extremely demanding task. Lack of confidence in English prevents us from communicating not only with colleagues but also with strangers and persons fluent in speaking in English from other countries. Inability to speak hampers our ability to express our opinions and feelings in a correct and consistent manner. It is important that whenever the need arises to participate, take initiative to speak even if your pronunciation is bad. One has to overcome the fear of embarrassment and speak. Its ok to commit a few mistakes in the beginning. Gradually, the comfort level will develop. This will allow you to break the vicious circle that has kept you professionally deaf and dumb.

\section{Talking}

The real crux of communication lies in talking. Wondering the difference in speaking and talking. For speaking on a certain topic, one may come prepared and communicate views. While talking is an interactive process between two or more persons and invariably it has to be extempore. The need of vocabulary in both cases is different. You may need to speak common words as well as the specialized medical terminologies and that too extempore. The best way is to carefully make notes on the medical terms and write your own personal medical English book because medicine is so specialized nowadays that even physicians of the same speciality have difficulty in understanding each other talking about specific matters.

During the interactive talking, many times it so happens that the you know the basic word or words, also know the key concept, and understand the sentence but you fail to bring out the phrasal words or medical term to properly express it. You fail to make natural sentences with them. The need in this case is not just to be understood but to express your thoughts and feelings appropriately and in an impressive manner. Expertise and experience in communicating in English language shows you out as a trained medico. The best way out in such a case is to copy the actors in theater. Imagine yourself taking part in these conversations. Write your own sentences and repeat them in front of a mirror until your process of talking appears natural.

\section{Writing}

Writing is the last step in learning English as a language. It is necessary to learn writing to take notes while you are in a classroom. Mostly, the talk of a teacher and statements made during the lecture are far more useful than what is written in the textbooks. Modern communication technology, the computer, the mobile, and the internet have changed the process and style of writing. To a certain extent, these technologies have made writing in English easier. But one needs to understand the difference between writing a commonly understood language and the English language needed to communicate in medical terms. Initially, the medical terminologies would appear alien to you, while the seniors would like to convince you not to worry and these will come by easily. Both the facts are correct. There is need to understand that most medical terms have not just originated from English, they are of Latin or Greek origin. There is need to understand and master the medical terminologies properly.

\section{ConClusion}

Medical education is undergoing a tremendous evolution. One of the most positive developments is the inclusion of English and communication skills module in the foundation course of the new undergraduate curriculum. It will definitely have a long-term impact on the betterment of medical students as professionals and as healers. Medical education with sound knowledge of English is the need of the hour and a domain that truly deserves attention.

\section{References}

1. MCl. 2018. Competency Based Undergraduate Curriculum for the Indian Medical Graduate. Medical Council of India, Sector-8, Dwarka, New Delhi.

2. MCI. 2018. Attitude, Ethics and Communication (AETCOM) Competencies for the Indian Medical Graduate 2018. Medical Council of India, Dwarka, New Delhi.

3. Lucaya J, 2005. In Foreword to "Medical English by Ribes, Ramon and Pablo R. Ros. 2006. ISBN-10 3-540-25428-5 Springer Berlin Heidelberg.

4. Ramon R, 2005. In Preface to Medical English by Ribes, Ramon and Pablo R. Ros. 2006. ISBN-10 3-540-25428-5 Springer Berlin Heidelberg.

5. https://www.hunimed.eu/course/medtec-school/test-preparationcourse/ (Downloaded January 31, 2020).

6. $\mathrm{MCl}, 2019$. "Foundation Course for the Undergraduate Medical Education Program 2019". Medical Council of India, Dwarka, New Delhi. 